\title{
Development of the regional innovative process in the space by Minkowski
}

\author{
Vitaly S. Borovik \\ Scientific and Technical Advisory Council \\ at the Head of the \\ Administration of Volgograd \\ Chair \\ Volgograd, Russia \\ borovikv@mail.ru
}

\author{
Vitaly V. Borovik \\ State Public Institution of the Volgograd region \\ "Directorate for Automobile Roads" \\ Capital Construction Department \\ Chief Specialist \\ Volgograd, Russia \\ Borovikvv70@mail.ru
}

\author{
Irina V. Bogomolova \\ Volgograd State Technical University, \\ Institute of Architecture and Civil Engineering \\ Chair of Management and Development of \\ the Municipal Economy and Construction \\ Volgograd, Russia \\ bogirvik@gmail.com
}

\begin{abstract}
The production process in a region is studied within the theory of the space suggested by $\mathrm{H}$. Minkowski. In this type of the space the factors of production used in time are the object of an interrelated and interdependent process. It was determined that to every change of work $\Delta Y_{i}$ and to an infinite number $\Delta Y_{i}$ corresponds to an infinite number $\Delta T_{i}$. It was established that the essence of time in the production process is manifested in the fact that the system of the time vectors is collinear and is co-directional with the vector system of the performed work. The nonobservance of these conditions leads to an unbalance of the system. In practice this circumstance is manifested in the violation of the work schedule and consequently of the plan of the innovative process realization.
\end{abstract}

Keywords - management, time in $4 D$ dimension, production resources, collinear vectors

\section{INTRODUCTION}

The problem of the development of the innovative process in the Volgograd region is quite relevant especially in connection with the declared strategy of an active introduction of the program of the digital economy of Russia [1].

The tasks connected with the implementation of the innovation introduction are quite many sided and typical of the largest number of the regions of the country. In the Russian Federation the share of the innovative products in the total output amounts to only $8-9 \%$ [2].

There exist also serious difficulties in the innovations introduction even in the countries with a developed economy, for instance, in the USA or in France «... Why is it so difficult to create and to support the potential for innovations? The existence of the problem of the innovations' amelioration is explained by the absence of the innovative strategy» [3]. In France we can find the following statement: «The realization of the national research and the innovative strategy is one of the main duties of a nation» [4].

The conception of C.R. McConnell and S.L. Brue about the functioning of the market economy is significant for our analysis. They declare that the possibility of the economic system to adapt to changes, to achieve the suitable corrections because of changes in the consumer demand, in the supplies of resources and the production technologies are a fundamental question in the market conditions [5].

Here it is appropriate to give here the opinion of A.A. Bogdanov who convincingly proved that «every system of the movable equilibrium has a tendency to change in a way so that the effect of the external influence could be reduced to a minimum» [6]. It is also one of the important aspects of the role of the organizational science under the conditions of the innovative development.

The forecasting of the influence of the innovative process on the economic indices of the functioning of production systems is one of the important conditions of its implementation. The growth of the number of the methods of the calculation of the forecasted economic parameters when planning the innovative process is thought to be a positive manifestation as the multiple calculations of the same value by means of various methods allows eliminating major mistakes. In order to confirm this idea the opinion of the academician V.M. Polterovich can be given: «... in the assessment of the 
impact of the IT on the rate of the economic development in the world with the help of numerous scientists and specialists serious miscalculations were made» [7].

There exist a number of other examples from the practice of the economic forecasting calculations which lead to a considerable excess of expenditures. For instance 10 billion pounds were spent on the construction of a unique tunnel under the English Channel and this sum exceeded the amount of the forecasted expenses two times [8].

The aim of the research is the development of the model allowing to forecast the innovative process on the economic parameters in adequate form and to exercise the administration in a more efficient way.

\section{MATERIALS AND Methods (Model)}

For modeling the innovative process in space and time the selection of the adequate mathematic base has an extraordinary importance. There are no doubts that the support of any productive idea is directed on the reduction of the resource inputs per unit of production. As it is well known the most frequent index reflecting the total assessment of the use of natural resources is the labour production. Its significant disadvantage consists in the fact that it does not take into account the total volume of resources indispensible for the realization of the working task. On its basis it is impossible so far to estimate the labour input and investments into the rate of the economic development, the role of extensive and intensive factors of the production development in it.

At the present time the production function is the most adequate economic and mathematical qualitative relation between the product output, factors of production (resources) and technology $[9,10]$. The production function, for instance Cobb-Douglas function, is the most simple and accessible model for the understanding of the process under analysis. In the opinion of the academician P.A. Minaker a valuable characteristic of the production function is the opportunity of the exercising the control of the calculation and the exactness of the assessment of the obtained results. This allows avoiding major mistakes at the calculation of the needed parameters [11].

It is well known that every regional production function is characterized by an individual production function of the resource use. Let's take for instance the production function of type (1):

$$
Y=C_{0} \prod_{i=1}^{n} x_{i}^{\alpha_{i}},
$$

Where $Y$ - the calculated index (for instance, profit, gross regional product, amount of work and others in natural, material or in qualitative expression); $x_{i}, i=\overline{1, n}$ factors (resources, for instance) influencing $Y$ (in natural, material or in qualitative expression); $\alpha_{i}, i=\overline{1, n}$ exponent characterizing the input of $x_{i}$ into $Y ; C_{0}$ coefficient characterizing the total impact of the factors that are not covered by the model.
Let's make the analysis of the production function of two production systems:

$$
Y_{1}=2,231 x_{1}^{1.123} x_{2}^{0.934} ; \quad Y_{2}=1,037 \quad x_{1}^{0.672} x_{2}^{0.785},
$$

Here $x_{1}$ - fixed and working capital; $x_{2}$ labour inputs. Let's assume that these production functions have equal resources. However the exponents in the first production function is higher than in the second one. Besides the influence of the factors that were not taken into account by the model $C_{0}$ is twice more considerable in the first production function than in the second one. Finally we get $Y_{1}>Y_{2}$. It is worth mentioning that this equation was obtained at absolutely equal volumes of the resources spent.

On the basis of this intermediate conclusion we suggest considering the realization of the innovative process in the production function as an algebraic introduction of some differentiation operators $d x_{i}, \quad i=\overline{1, n}$ relative to the corresponding factors $x_{i}$ (resources) in its production function.

For instance the introduction of progressive technologies can contribute to the growth of the fixed capital. As a rule the use of the highly productive machines and mechanisms contributes to the increase of the working capital consumption (growth of materials consumption and others) i.e. leads to the growth of $x_{1}$. Let's assume that the increase of the working capital is accompanied by the reduction of the labour inputs $x_{2}$. Consequently in the production function the expression $d x_{1}-$ $d x_{2}$ need to be introduced into the production function. It is obvious that the efficiency of the calculation of these differentials (changes in resources) can be various depending first of all on the quality of the process management. It can be stated a priori that at other equal conditions the introduction in the first production function of the first production system of the differentials of resources $d x_{i}$ will give a higher growth of $\Delta Y_{1}$ as the resources in the first production system are used more efficiently.

\section{RESULTS AND DISCUSSION}

The understanding of the necessity of exactness and reliability growth of the planned characteristics of the innovative process determined the development of principally new approaches to their definition. As we know any economizing is finally reduced to the gain of time. The most extensive studies are made in the direction of the optimization of the role of time in the cost of the object (creation of product). However in the opinion of $\mathrm{H}$. Minkowski «... the space itself and time itself are expected to transform into fictions ...» [12]. When using the term "space" we mean resources. The existing attempts of the solution of the economic tasks as a process in the multidimensional space, in particular in 4D dimension, with the help of time are realized through the visualization. For instance in the opinion of a number of the authors $[13,14]$ the use of 4D model is a useful alternative to the project of forecasting of tools like SRM nets or bar charts at the technical and economic explanation. The opportunity to understand the process by a large number of specialists appears and the ability to anticipate the potential space and time conflicts and tasks also arises. The necessity of 
the improvement of 4D tools which are expected to include bar charts, component lists and their annotations in the graphical user interface is emphasized [13]. The visualization of the transport projects in $4 \mathrm{D}$ is an efficient way of the information exchange between the parties involved in the project is examined [14]. In the computer applications the visualization is mainly used for the information transfer about the geometric construction of a photorealistic presentation of the transport projects. It is thought that the use of the 4D visualization is efficient also in the process of the realization of these projects for the facilitation of the joint decision making in the construction planning and in the planning of the work schedule. However $4 \mathrm{D}$ visualization is limited by the highlighting with different colours of various works or operations executed in different times.

With the increase of the complexity of modern for instance construction projects there exists an urgent necessity in a higher efficiency of the personal computer use for the achievement of efficient planning and management $[15,16$, 17]. The authors distinguish between the earlier inventions and the introduction of the prototypes of four dimensional model of the site administration (4DSMM). It is suggested to do the planning by means of a three dimensional computer model of the task where the opportunity to view the graphics in colour of the modelling process during the hypothesized period of time is given to the specialists in planning. The colour is thought to be the fourth parameter in the 4D model where every colour relates to a definite period of time corresponding to a work stage or work type. However the time is not correlated with a common model which allows optimizing the costs.

The production process is not seen as a system where the result of the use of resources in time is the object of the interrelated and interdependent analysis. The solution of the problem in the 4D space where time finds the reflection only in colour excludes the use of the metric space (the geometric interpretation of the time and space).

\section{A. Essence of time in the production process by Minkowski}

In the space interpreted by Minkowski three space dimensions and one time dimension are used. All the four dimensions are organically connected into a single entity being almost equivalent and within some limitations capable of transferring one into another.

As it is well known the geometric properties of the four dimensional space (space by Minkowski) are determined by the equation for the square distance between two events (interval) $s^{2}$ :

$$
s^{2}=c^{2}(\Delta x)^{2-}(\Delta y)^{2}-(\Delta z)^{2}
$$

Here $(\Delta x)^{2},(\Delta y)^{2},(\Delta z)^{2}$ are the variations of the difference of the event coordinates and $(\Delta T)^{2}$ is the difference of their moments in time and $c-$ is the velocity of light in vacuum [13].

In this respect it is worth mentioning the explanation of A. Einstein about the role of the light velocity. The authors emphasize that the theory of relativity has been often criticized for the fact that it unreasonably gives the central theoretical role to the passage of light and it bases the notion of time using its laws. The state of matters is however the following. In order to give the notion of time the physical sense some processes are needed that would give the opportunity of establishing the relation between various points of space. The questions about the types of processes that are selected in such a definition is insignificant. For the theory it is good of course to choose only those processes about which we know something definite. The passage of light in the vacuum thank to the research of Maxwell and Lorentz is good for this goal to a greater extent than any other process that could become the object of the analysis [18].

Here a very important conclusion can be made. In the system (1) $c$ - is the velocity of light in the vacuum is a constant. For the solution of an applied problem it can be replaced by a constant which in a higher degree satisfies the requirements of the process under analysis in a region. For instance the productivity (conventionally maximal or normative) can be taken as $Q$. Then $q$ is the productivity characterizing the system where the innovative process is planned.

When we use this explanation for the solution of the managerial task in the generalized four dimensional space the expression (1) can be presented in the following form. $s^{2}=\left(d x^{0}\right)^{2}-d x_{1}^{2}-d x_{2}^{2}-d y^{2}$,

Here: $x_{1}$ - labour; $x_{2}$ - capital (fixed and working); $y$ - for instance volume of works (production). Тогда $\mathrm{x}=Q t$. Let's analyze the realtion:

$$
\Delta Y_{i}=Q(t) \Delta T_{i},
$$

Here: $\Delta Y$ - growth of the volume of works (production) in the monetary or natural and material expression; $Q(t)-$ productivity; $\Delta T$ - period of time for the realization of $\Delta Y$. However as we see in Figure $1 \Delta Y$ is a vector, $Q$ is a scalar. It is worth focusing the attention on the fact that if we fix all material factors of production the formula (4) shows that the performed volume of work $\Delta Y$ is the function of time. At a fixed value of $\Delta Y$ the expression (4) is the equation with two indeterminates in particular $Q(t)$ and $\Delta T$. It is known that such an equation tolerates an infinite multitude of solutions $\left(Q_{\mathrm{i}(\mathrm{t})}\right.$; $\Delta T), i \in n$ and none of them can do without $\Delta T$. If $\Delta Y=$ const, so practically indefinite influence of $Q(t)$ and $\Delta T$ on each other becomes obvious. Here the conclusion can be drawn. If $Q(t)$ is determined by the intensity of use of the physical factors so $\Delta T$ influencing through (4) on $\Delta Y$ behaves just like physical factors i.e. is a production factor (resource).

If time is a production resource this fact should be taken into consideration within the processes of work planning. Time is expected to be seen not only as the "continuity" in the fourth dimension but also a factor influencing the productivity. Thus not all the parameters (4) are interrelated and interdependent:

$$
\Delta \mathrm{R}=\mathrm{R}_{2}-\mathrm{R}_{1} \cdot \Delta \mathrm{Y}=\Delta \mathrm{R}-\nabla \mathrm{Y}\left|\mathrm{X}-\mathrm{X}_{1}=\mathrm{R}_{2}-\mathrm{R}_{1}-\nabla \mathrm{Y}\right| \mathrm{X}-\mathrm{X}_{1}
$$




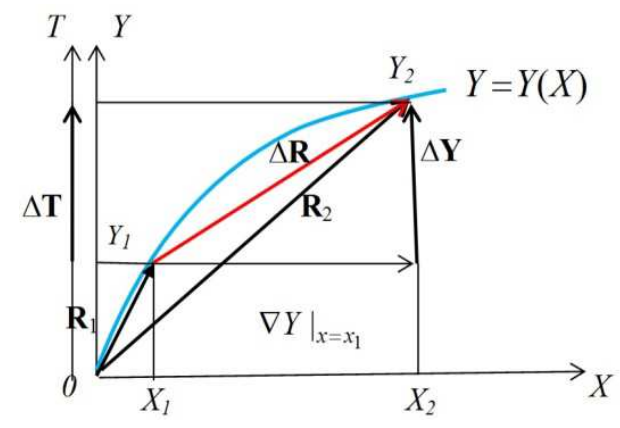

Fig. 1. Illustration of the relative situation of the vectors $\Delta T$ and $\Delta Y$

$$
\text { Here } \nabla=\frac{\partial}{\partial x_{1}} e_{1}+\frac{\partial}{\partial x_{2}} e_{2} \text {. }
$$

So the formula (4) should be presented like this:

$$
\Delta \mathrm{Y}=Q(t) \Delta \mathrm{T}_{i},
$$

For the conservation of the equation (4) it is indispensible that $\Delta T$ should also be a vector (tensor of first rank). Hence $\Delta T_{i} \uparrow \uparrow \Delta Y_{i}$ the vectors of time $\Delta T_{i}$ and the growth of the production output $\Delta Y_{i}$ are collinear and codirectional.

\section{B. Lorentz quasi conversion}

The use of the metric space or the geometric interpretation of the time and space allows defining the essence of time in a specific production process. It is manifested in the fact that the system of the vectors of the time growth is collinear and codirectional relative to the corresponding vectors of the work volume growth. At the same time the vector of time growth corresponds to the vector of the work volume growth. The non performance of these conditions leads to a misbalance in the system what is manifested in practice in the disruption of a schedule and consequently in the delay in the innovative process. These are the determining conditions for the implementation of the managerial process.

In passing from one inertial reference frame to another one the spatial coordinates and time are converted one through another by means of the Lorentz quasi conversion. It is known that the frame of reference is inertial if any point in space free from the interaction with other objects (isolated one) moves uniformly and rectilinearly. In the special theory of the relativity the coordinates $(x, y, z, t)$ of every event from one isolated point to another are subject to the Lorentz conversion. Similarly the coordinates of every fourth vector are converted [19].

The changes in the managerial process are implemented at the collinear spatial axes if the inertial reference system $K^{\prime}$ moves relative to the inertial reference system $K$ with a constant velocity. In our problem when we use the term "velocity" we mean the productivity $q$, typical for an inertial reference frame in which the innovative process is planned. Correspondingly $Q$ is the maximal productivity taken as a standard which can be characteristic for a progressive production system or set as norm by regulators as a constant in the region. The origin of coordinate coincides in the starting time moment in both systems [20].

If we consider that the Lorentz conversions are the changes which conserve the Minkowski metric unchanged what means that the latter conserves in its presence the simplest form at the conversion from one inertial system to another. The Lorentz transformations are the analogue for the Minkowski metric of the orthogonal changes converting from one orthonormalized basis (basis constructed from the paired orthogonal vectors) to another or making the generalization of the concept of the motion in the Euclidean space. The total group of the transformation consists in the combination of the spatial reflections in time and the transformation which from the physical point of view are the changes of the conversion from one isolated point to another [21]. Then the direct Lorentz quasi conversion for the solution of a managerial problem in the three dimensional space will get the form:

$$
x_{1}^{\prime}=\frac{x_{1} q t}{\sqrt{1-\frac{q^{2}}{Q^{2}}}}, \quad x_{2}^{\prime}=x_{2}, \quad y^{\prime}=y, \quad t^{\prime}=\frac{t-\left(\frac{q}{Q^{2}}\right) x_{1}}{\sqrt{1-\frac{q^{2}}{Q^{2}}}} .
$$

The complex of the obtained relations create the prerequisites for the development of the software that allows making forecasts of many situations of the regional innovative process and allows atomizing the management process.

\section{CONCLUSION}

On the basis of the main provisions of the Minkowski space theory it was shown that in the production process time and resources (capital funds, materials and labour) are to be analyzed as interrelated and interdependent factors. The theoretical justification is based on the explanation of A. Einstein about the change of the constant $c$ that is the velocity of light in the geometric construction space-time of the relativity theory for another parameter, for instance $Q$ or productivity which suits more the process under analysis. It was proved that time in a specific production process can be presented as a system of vectors of the time growth $\Delta T_{i}$ and this system is collinear and codirectional to the vector of the work (production) volume growth $\Delta Y_{i}(i=1,2, \ldots \infty)$. To every $\Delta Y_{i}$ corresponds $\Delta T_{i}$ and to an infinite number $\Delta Y_{i}$ corresponds an infinite number $\Delta T_{i}$. It was shown that the inequality of the production process determines the "contractibility" and the "expansion" of time parameter together with the growth change of the work volume $\Delta Y$ and productivity $Q(t)$. On the basis of the Lorentz quasi conversion the relations were obtained which allow solving the problems of the administration of the regional innovative process in space and time according to the theory of Minkowski.

\section{References}

[1] Goncharova E.B., Popova Ya.V. Innovatsionnaya akvtinost' Volgogradskoi oblasti: problemy, dinamika, perspektivy [Innovative activity of the Volgograd region: problems, dynamics and prospects]. Mezhdunarodnyi zhurnal prikladnykh i fundamental'nykh issledovanii [International journal of applied and fundamental research], 2015, № 124, pp. 692-696; 
[2] Decree of the President of the Russian Federation "About the strategy of the scientific and technological development of the Russian Federation" dated December, $1^{\text {st }} 2016$ N 642.

[3] Pisano G.P. You Need an Innovation Strategy. Harvard Business Review. From the June 2015 Issue. Available at: https://hbr.org/2015/06/you-need-an-innovation-strategy Date of reference 01.01.2018.

[4] National Research and Innovation Strategy. General Report. Ministry for higher education and research. France, 2009, p.11

[5] McConnell C. R., Brue S. L. Economics. McGraw-Hill Publisching Company. NewYork. 1990, p.81.

[6] Bogdanova A.A. Tektologiya: vseobshchaya organizatsionnaya nauka [Tectology: universal organizational science]. Third edition: revised and completed. - Moscow, 1989. Available at: http://gtmarket.ru/laboratory/basis/5909._Date of reference 07.01.2018.

[7] Polterovich V.M. Gipoteza ob innovatsionnoi pauze i strategii modernizatsii [Hypothesis of the innovative break and modernization strategy]. Voprosy ekonomiki [Voprosy ekonomiki], 2009, №6, p. 12.

[8] Tonnel' pod La-Manshem [Tunnel under the English Channel]. Available at: http://krasivijmir.ru/angliya/tonnel-pod-la-manshem.html. Date of reference 15.01.2018.

[9] Goncharova E.B., Popova Ya.V. Innovatsionnaya akvtinost' Volgogradskoi oblasti: problemy, dinamika, perspektivy [Innovative activity of the Volgograd region: problems, dynamics, prospects]. Mezhdunarodnyi zhurnal prikladnykh i fundamental'nykh issledovanii [International journal of applied and fundamental research], 2015, № 124, pp. 692-696;

[10] Bessonov V.A. Problemy postroeniya proizvodstvennykh funktsii v rossiiskoi perekhodnoi ekonomike [Problem of the construciton of produciton functions in the Russian transition economy]. Available at: http://www.economicus.ru/macroeconomica/readings/Prois_funk.pdf Date of reference: 11.01. 2018.

[11] Borovik V.S. Borovik V.V., Prokopenko Yu.E. Model' upravleniya vnedreniem novoi tekhnologii na osnove proizvodstvennoi funktsii [Model of the management of the introduction of a new technology on the basis of the production function]. Ekonomicheskii analiz: teoriya praktika [Economic analysis: theory and practice], 2013, № 42 (345), pp.25-30.

[12] Minaker P.A., Mashtaler T.N., Prokopenko O.M. Predplanovoe issledovanie faktorov regional'nogo ekonomicheskogo rosta [Preplan study of the factors of regional economic growth]. Review of the Academy of Sciences. Siberian Branch. Series of social sicences, 1982, Issue.1, №1.

[13] Minkowski G. Prostranstvo i vremya [Space and time]. Saint Petersburg: Knigoizdat. Physics, 1911, 94 p.

[14] Gaikwad P. G., Prashant N. N., Nilesh Patil. Analysis of Time and Cost Overruns in Road Project. Journal of Construction Engineering, Technology \& Management, 2016, V 6, № 2, pp. 42-51.

[15] Ming Li, Guangdong Wu. Robust Optimization for Time-Cost Tradeoff Problem in Construction Projects. Abstract and Applied Analysis, 2014, Volume 2014, Article ID 926913.

[16] Shannon B. Terry and Gunnar Lucko. Algorithm for Time-Cost Tradeoff Analysis in Construction Projects by Aggregating Activity-Level Singularity Functions Construction Research Congress 2012. Available at: http://rebar.ecn.purdue.edu/crc2012/papers/pdfs/-55. Date of reference 01.01.2018.

[17] Dabhade U.D., Hedaoo N.A., Gupta L.M., and Ronghe G.N. Time and Cost Evaluation of Construction of Steel Framed Composite Floor with Precast Concrete Floor Structure. Proceedings of the 26th International Symposium on Automation and Robotics in Construction (ISARC 2009)

[18] Einstein A. Sushchnost' teorii otnositel'nosti [The relativity theory]. Moscow: Izdatel'stvo inostrannoi literatury Publ., 1955, p. 28.

[19] Vektornyi analiz. Matematicheskaya entsiklopediya [Vector analysis. Mathemetical encyclopedia]. Vol1. Moscow: Izdatel'stvo «Sovetskaya entsiklopediya» Publ, 1977. p. 648.

[20] Carmeli, M. Group Theory and General Relativity, Representations of the Lorentz Group and Their Applications to the Gravitational Field, McGraw-Hill, New York, 1977, 311 p.

[21] Pan V. Fizika prirody prichinno-sledstvennykh svoistv prostranstvennogo fizicheskogo vremeni [Physics of the nature of the cause and effect peculiarities of the spatial phsysical time]. Available at: http://otvp.info/arx_in/1_rrouqa/a102_in_rus.php. Date of reference 15.01.2018 